\title{
IMPACT OF ADVERSE DRUG REACTIONS OF TOPICAL ANTI-GLAUCOMA MEDICATIONS ON THE VISION-RELATED QUALITY OF LIFE IN PRIMARY OPEN ANGLE GLAUCOMA
}

\author{
Neeta Sidhan1, Beena Thankappan², Georgey C. Joshy³, Safna N. Fazil4 \\ ${ }^{1}$ Assistant Professor, Department of Ophthalmology, Trivandrum, Kerala. \\ ${ }^{2}$ Assistant Professor, Department of Ophthalmology, Trivandrum, Kerala. \\ ${ }^{3}$ Postgraduate Trainee, Department of Pharmacy Practice, College of Pharmaceutical Sciences, Government Medical College, \\ Trivandrum, Kerala. \\ ${ }^{4}$ Postgraduate Trainee, Department of Pharmacy Practice, College of Pharmaceutical Sciences, Government Medical College, \\ Trivandrum, Kerala.
}

\begin{abstract}
BACKGROUND
Adverse drug reactions (ADR) to topical medications form an important cause for noncompliance in the long term management of glaucoma. This study was aimed to determine the different types of adverse drug reactions associated with glaucoma medications and their impact on the vision-related Quality of Life (vQOL) in patients with Primary Open Angle Glaucoma.
\end{abstract}

ABSTRACT

\section{MATERIALS AND METHODS}

Patients with Primary Open Angle Glaucoma, fulfilling the inclusion criteria were interviewed and data collected. Adverse drug reactions to topical anti-glaucoma medications were evaluated using the 'Comparison of Ophthalmic Medications for Tolerability Questionnaire' and quality of life related to vision was evaluated using the 'National Eye Institute Visual Function-25 Questionnaire'. Statistical analysis was performed using the SPSS version 22. The effect of ADR on the vQOL was analysed both by a univariate and multivariate analysis using a linear regression model.

\section{RESULTS}

The study population included 115 patients (28\% females) with mean age of $53.22 \pm 11.46$ years. At least one adverse drug reaction was reported in $71.2 \%$ of cases. Adverse drug reaction (ADR) was reported in nearly all patients on dorzolamide eye drops followed by timolol (74.1\%), brimonidine (50\%), bimatoprost (31.8\%), latanoprost (39.3\%) and travoprost (15\%). The three most common adverse drug reactions reported were burning (60.75\%), blurred vision (45.56\%) and bitter taste (44.3\%). The vision-related Quality scores in all subset domains were well above 50, the lowest being the general health and near activities domain. Significant association was noted between patients with ADR and low vQOL scores $(P=0.03)$ on multivariate analysis.

\section{CONCLUSION}

Adverse drug reactions to topical anti-glaucoma medications were found to have a negative impact on the vision-related quality of life in glaucoma patients, emphasising the integration of proper patient education and counselling in the long-term management.

\section{KEYWORDS}

Adverse Drug Reactions, Anti-glaucoma Medications, Quality of Life.

HOW TO CITE THIS ARTICLE: Sidhan N, Thankappan B, Joshy GC, et al. Impact of adverse drug reactions of topical anti-glaucoma medications on the vision-related quality of life in primary open angle glaucoma. J. Evolution Med. Dent. Sci. 2017;6(56):42014205, DOI: $10.14260 /$ Jemds/2017/910

\section{BACKGROUND}

The term 'Glaucoma' relates to a group of conditions characterised by distinctive optic neuropathy and visual field loss, raised intraocular pressure being the major risk factor. It is one of the leading causes of irreversible blindness worldwide. ${ }^{1,2}$ The estimated prevalence of glaucoma in India is about 11.9 million $^{2}$ and the country is expected to be the second largest home to glaucoma by $2020.1,3$

Financial or Other, Competing Interest: None.

Submission 08-06-2017, Peer Review 02-07-2017,

Acceptance 08-07-2017, Published 13-07-2017.

Corresponding Author:

Neeta Sidhan,

Regional Institute of Ophthalmology,

Red Cross Road,

Vanchiyoor - P. O.,

Trivandrum-695035,

Kerala, India

E-mail: neetasidhan@yahoo.co.in

DOI: $10.14260 /$ jemds $/ 2017 / 910$

Primary Open Angle Glaucoma (POAG) has been referred to as "the silent thief of sight," as most patients are unaware of the disease until permanent visual damage ensues. The cornerstone of treatment for POAG involves reduction of intraocular pressure by medical, laser or surgical means. In majority of patients, medical treatment with topical medications alone is said to achieve the target pressure that prevents further progression of the disease. However, ensuring lifelong adherence, tolerance and compliance to topical medications form a critical issue in the long-term management of the disease.

A subjective assessment of Adverse drug reactions (ADR) associated with topical glaucoma medications and visionrelated quality of life (vQOL), using validated patientreported outcome (PRO) questionnaires form an important tool in understanding the impact of glaucoma and its treatment on the daily life activities of an individual. However, vQOL has been perceived to differ between individuals, with variability based on cultural beliefs, social circumstances and personal expectations. ${ }^{4}$ 
This study was hence designed to determine the different types of ADR associated with topical glaucoma medications and its effect on the vision-related quality of life in patients with POAG attending the Glaucoma Clinic in a tertiary teaching eye hospital in Kerala, India.

\section{MATERIALS \& METHODS}

This cross-sectional observational study was conducted at a tertiary eye hospital in Kerala, South India during JulyDecember, 2016. The participants included POAG cases above 40 years of age who were on treatment with topical glaucoma medications. The diagnostic criteria included baseline intraocular pressure above $22 \mathrm{mmHg}$, open angles on gonioscopy, characteristic glaucomatous optic nerve disc changes and corresponding visual field defects. The exclusion criteria included patients on chronic ocular medication other than anti-glaucoma drugs, patients with prior ocular surface disorders, corneal disorders, ocular inflammations and patients with chronic systemic diseases that would affect the QOL such as diabetes, arthritis, neurological disorders, cardiac diseases and malignancies. The study was approved by the institutional ethics committee and was conducted in adherence to the tenets of the Declaration of Helsinki.

Information relevant to the study was collected by direct interview of the patients. The sociodemographic data and history related to glaucoma of each patient was recorded. The ADR of topical anti-glaucoma drugs was assessed using the 'Comparison of Ophthalmic Medications for Tolerability (COMTOL) questionnaire'.5, 6, 7 The COMTOL questionnaire is designed and validated for comparing the tolerability of topical glaucoma medications. ${ }^{8}$ The ocular symptoms listed are burning, stinging, conjunctival hyperaemia, itching, ocular secretion, ocular pain, tearing, brow ache, dryness, foreign body sensation, eyelid redness and eyelid oedema. The other domains included frequency and bothersomeness of blurred vision, accommodation difficulties and taste side effects as well as limitations on driving, reading and moderate activities.

The vision-related quality was assessed using the 'National Eye Institute- Visual function questionnaire 25' (NEI VFQ-25). ${ }^{9}$ A local language (Malayalam) validated questionnaire was used to record the data. The VFQ-25 consists of a base set of 25 vision targeted questions representing 11 vision-related domains, plus an additional single-item general health rating question. The visiontargeted domains are related to a specific functional ability, for which the patient grades a response reflecting the severity of the problem. Subset scores reflect the impairment related to each domain and the total score reflects the composite QOL. The different subsets and the number of inclusive questions (in brackets) include: global vision rating (1), difficulty with near vision activities (3), difficulty with distance vision activities (3), limitations in social functioning due to vision (2), role limitations due to vision (2), dependency on others due to vision (3), mental health symptoms due to vision (4), driving difficulties (3), limitations with peripheral (1) and colour vision (1), and ocular pain (2). Additionally, it also contains a single general health rating question which has been shown to be a robust predictor of future health and mortality in several population-based studies. ${ }^{9}$
Statistical analysis was performed using the SPSS version 22. Descriptive statistics of the sociodemographic data, data relating to glaucoma treatment and ADR of glaucoma medications were analysed. NEI-VFQ-25 QOL scores were calculated according to the instrument author's algorithm. The effect of ADR on the vQOL were analysed both by a univariate and multivariate analysis using a linear regression model. Comparison of variables in patients with and without ADR were done using Chi square and t test.

\section{RESULTS}

One hundred and fifteen (115) cases of POAG were enrolled for the study, out of which 4 were excluded later due to incomplete data. The mean age was found to be $53.22 \pm 11.46$ years. Males constituted $72.1 \%$ while females formed $27.9 \%$ of the study group. Nearly half the total number of patients resided in rural areas and $38.7 \%$ belonged to the low socioeconomic group. The duration of medical treatment for glaucoma was found to be more than 5 years in $4.5 \%$ of patients; $1-5$ years in $65.8 \%$ of patients and less than 1 year in $29.7 \%$ of patients.

Timolol was the most prescribed drug in nearly $52.3 \%$ patients followed by latanoprost (25.2\%), Travoprost (18\%), Bimatoprost (19.8\%), Brimonidine (19.8\%) and Dorzolamide (4\%.) Fixed combination drug (Dorzolamide with timolol) was used only in $9 \%$ of patients. At least one ADR was reported in about $71.2 \%$. ADR was reported in nearly all patients on dorzolamide and (dorzolamide + timolol) combination. This was followed by timolol (74.1\%), brimonidine (50\%), bimatoprost $(31.8 \%)$, latanoprost (39.3\%) and travoprost (15\%). The most common ADR reported was burning $(60.75 \%)$ followed by blurred vision (45.56\%), bitter taste (44.3\%), dry eye (34.17\%), redness (26.58\%), tearing $(20.25 \%)$, itching $(18.98 \%)$ and stinging (13.92\%).

The vQOL scores in different domains among POAG patients are shown in Table 1. All subset domain scores were above 50. The lower scores were found within the general health and near activities domain. The scores related to domains of social functioning, mental health and dependency showed high scores above 70. A univariate analysis of ADR and vQOL scores in different domains are shown in Table 2. All domains except driving showed statistically significant lower values in patients with ADR. Comparison of the sociodemographic and glaucoma treatment parameters among patients with and without ADR are shown in Table 3 and 4 . There was no statistically significant difference in terms of age, gender and duration of treatment. However, ADR was more common among patients in the low socioeconomic group $(p=0.001)$, rural residence $(p=0.006)$ and multiple drug use $(\mathrm{p}<0.001)$.

Multivariate analysis of the different variables and vQOL scores are shown in Table 5. Significant relationship was noted between patients with ADR and poor vQOL scores (P = 0.03). The rural area of residence, prolonged duration of treatment for glaucoma (more than 5 years), and multiple drug use also showed significant associations with low vQOL scores. 


\begin{tabular}{|c|c|c|c|c|c|c|c|c|}
\hline Domains & $\mathbf{N}$ & Mean & SD & Minimum & Q1 & Median & Q3 & Maximum \\
\hline General Health & 111 & 55.6 & 18.1 & 25.0 & 50.0 & 50.0 & 75.0 & 100.0 \\
\hline General vision & 111 & 64.9 & 15.8 & 40.0 & 60.0 & 60.0 & 80.0 & 80.0 \\
\hline Ocular pain & 111 & 68.7 & 19.6 & 37.5 & 50.0 & 62.5 & 87.5 & 100.0 \\
\hline Near activities & 111 & 57.5 & 26.7 & 12.5 & 41.7 & 50.0 & 83.3 & 100.0 \\
\hline Distant Vision & 111 & 62.8 & 28.0 & 12.5 & 37.5 & 75.0 & 87.5 & 100.0 \\
\hline Social Function & 111 & 70.9 & 30.4 & 25.0 & 37.5 & 87.5 & 100.0 & 100.0 \\
\hline Mental Health & 111 & 74.9 & 18.6 & 31.3 & 62.5 & 81.3 & 93.8 & 100.0 \\
\hline Role Limitation & 111 & 67.5 & 26.8 & 25.0 & 50.0 & 75.0 & 100.0 & 100.0 \\
\hline Dependency & 111 & 77.1 & 23.2 & 16.7 & 66.7 & 75.0 & 100.0 & 100.0 \\
\hline Colour vision & 111 & 78.4 & 30.1 & 25.0 & 50.0 & 100.0 & 100.0 & 100.0 \\
\hline Peripheral Vision & 111 & 66.2 & 28.9 & 25.0 & 50.0 & 75.0 & 100.0 & 100.0 \\
\hline Driving & 23 & 73.6 & 20.7 & 25.0 & 58.3 & 75.0 & 91.7 & 100.0 \\
\hline \multicolumn{9}{|c|}{ Table 1. vQOL Scores in Glaucoma Patients } \\
\hline
\end{tabular}

\begin{tabular}{|c|c|c|c|c|c|c|}
\hline & \multicolumn{4}{|c|}{ ADR } & \multirow{3}{*}{$\mathrm{T}$} & \multirow{3}{*}{$\mathrm{P}$} \\
\hline & \multicolumn{2}{|c|}{ Absent (N =31) } & \multicolumn{2}{|c|}{ Present $(N=79)$} & & \\
\hline & Mean & Std & Mean & Std & & \\
\hline General Health & 61.3 & 12.6 & 53.5 & 19.5 & 2.063 & .042 \\
\hline General vision & 72.3 & 11.2 & 62.0 & 16.5 & 3.172 & .002 \\
\hline Ocular pain & 75.0 & 16.5 & 66.1 & 20.3 & 2.163 & .033 \\
\hline Near activities & 68.0 & 21.6 & 52.8 & 27.1 & 2.794 & .006 \\
\hline Distant Vision & 80.1 & 17.0 & 55.8 & 28.8 & 4.405 & .000 \\
\hline Social Function & 92.7 & 15.4 & 62.3 & 30.8 & 5.237 & .000 \\
\hline Mental Health & 84.7 & 12.8 & 70.9 & 19.1 & 3.695 & .000 \\
\hline Role Limitation & 75.0 & 22.1 & 64.1 & 27.9 & 1.949 & .054 \\
\hline Dependency & 87.1 & 16.6 & 72.9 & 24.2 & 3.000 & .003 \\
\hline Colour vision & 96.8 & 10.7 & 70.9 & 32.1 & 4.381 & .000 \\
\hline Peripheral Vision & 79.0 & 19.5 & 60.8 & 30.4 & 3.101 & .002 \\
\hline Driving & 79.2 & 19.4 & 70.6 & 21.3 & .950 & .353 \\
\hline & 2. $\mathrm{Co}$ & of & amo & vith & $A D R$ & \\
\hline
\end{tabular}

\begin{tabular}{|c|c|c|c|c|c|}
\hline \multirow{2}{*}{ ADR } & \multirow{2}{*}{$\mathbf{N}$} & \multicolumn{2}{|c|}{ Age (Years) } & \multirow{2}{*}{ T } & \multirow{2}{*}{$\mathbf{p}$} \\
\cline { 2 - 5 } & & Mean & 11.0 & .771 & .443 \\
\hline Absent & 31 & 54.6 & 11.8 & \\
\hline Present & 79 & 52.7 & & \\
\hline \multicolumn{2}{|c|}{ Table 3. Comparison of Age between Patients with and without ADR } \\
\hline
\end{tabular}

\begin{tabular}{|c|c|c|c|c|c|c|c|c|c|c|}
\hline & & \multicolumn{4}{|c|}{ ADR } & \multirow{2}{*}{\multicolumn{2}{|c|}{ Total }} & \multirow{3}{*}{$\chi^{2}$} & \multirow{3}{*}{ df } & \multirow{3}{*}{$\mathbf{p}$} \\
\hline & & \multicolumn{2}{|c|}{ Absent } & \multicolumn{2}{|c|}{ Present } & & & & & \\
\hline & & $\mathbf{N}$ & $\%$ & $\mathbf{N}$ & $\%$ & $\mathbf{N}$ & $\%$ & & & \\
\hline \multirow{2}{*}{ Sex } & Male & 21 & 67.7 & 58 & 73.4 & 79 & 71.8 & \multirow{2}{*}{0.354} & \multirow{2}{*}{1} & \multirow{2}{*}{0.552} \\
\hline & Female & 10 & 32.3 & 21 & 26.6 & 31 & 28.2 & & & \\
\hline \multirow{2}{*}{$\begin{array}{c}\text { Socio } \\
\text { economic } \\
\text { status } \\
\end{array}$} & *APL & 27 & 87.1 & 41 & 51.9 & 68 & 61.8 & \multirow[b]{2}{*}{11.686} & \multirow[b]{2}{*}{1} & \multirow[b]{2}{*}{0.001} \\
\hline & **BPL & 4 & 12.9 & 38 & 48.1 & 42 & 38.2 & & & \\
\hline \multirow{2}{*}{$\begin{array}{l}\text { Place of } \\
\text { residence }\end{array}$} & Urban & 22 & 71 & 33 & 41.8 & 55 & 50 & \multirow[t]{2}{*}{7.591} & \multirow[t]{2}{*}{1} & \multirow[t]{2}{*}{0.006} \\
\hline & Rural & 9 & 29 & 46 & 58.2 & 55 & 50 & & & \\
\hline \multirow{3}{*}{$\begin{array}{c}\text { Treatment } \\
\text { Duration }\end{array}$} & $<1$ year & 2 & 6.5 & 2 & 2.5 & 4 & 3.6 & \multirow{3}{*}{1.206} & \multirow{3}{*}{2} & \multirow{3}{*}{0.547} \\
\hline & $1-5$ years & 8 & 25.8 & 25 & 31.6 & 33 & 30 & & & \\
\hline & $>5$ year & 21 & 67.7 & 52 & 65.8 & 73 & 66.4 & & & \\
\hline \multirow{2}{*}{ No of drugs } & Single drug & 25 & 80.6 & 33 & 41.8 & 58 & 52.7 & \multirow{2}{*}{13.497} & \multirow{2}{*}{1} & \multirow{2}{*}{$<0.001$} \\
\hline & $>1$ drug & 6 & 19.4 & 46 & 58.2 & 52 & 47.3 & & & \\
\hline & & & npc & $b$ & Pati & it & ith & & & \\
\hline
\end{tabular}

Above $\left(^{*}\right)$ and below $\left(^{* *}\right)$ Poverty line. 


\begin{tabular}{|c|c|c|c|c|c|c|}
\hline & \multicolumn{3}{|c|}{ Univariate Analysis } & \multicolumn{3}{|c|}{ Multivariate Analysis } \\
\hline & Beta & $\mathbf{T}$ & $\mathbf{P}$ & Beta & $\mathbf{t}$ & $\mathbf{p}$ \\
\hline (Constant) & & & & & 12.413 & .000 \\
\hline Age in years & -.098 & -1.032 & .304 & -.095 & 1.260 & .211 \\
\hline Sex & -.006 & -.062 & .950 & -.080 & 1.071 & .287 \\
\hline Socioeconomic status & -.536 & -6.631 & .000 & -.042 & .491 & .625 \\
\hline Place of residence & -.204 & -2.179 & .031 & -.297 & 3.418 & .001 \\
\hline Duration of Treatment & -.405 & -4.621 & .000 & -.260 & 3.175 & .002 \\
\hline No. of drugs & -.538 & -6.665 & .000 & -.231 & 2.485 & .015 \\
\hline ADR & -.363 & -4.044 & .000 & -.175 & 2.207 & .030 \\
\hline
\end{tabular}

\section{DISCUSSION}

ADR related to topical anti-glaucoma medications and its implications on the vQOL has not been studied before in South Indian patients. In our study, the incidence of ADR was fairly common with $71 \%$ reporting at least one ADR. The three most common ADR reported was burning, blurred vision and bitter taste. However, no lethal or severe adverse effects were reported. In spite of ethnic and geographic differences, our results are comparable to similar studies from different parts of the world, such as Nordmann et al, 8 Pisella et al $^{10}$ and M Alaei11 et al (ADR in 62.4\%, 57\% and $50 \%$ respectively).

Timolol was found to be the most prescribed drug in about half the number of cases followed by Prostaglandin analogues, Brimonidine and Dorzolamide. ADR was reported in nearly all the patients treated with Dorzolamide and Dorzolamide + Timolol combination. This was followed by Timolol, Brimonidine and Prostaglandin analogues. This observation was different from other studies in which ADR related to Dorzolamide was less frequent while Brimonidine (Bhatt et al) ${ }^{12}$ and Latanoprost (M Alaei et al) ${ }^{11}$ were found to be the most frequent offending medications. Since the ADR could also be related to preservatives (Used in the topical drug preparations), it is difficult to make a definite conclusion regarding this observation.

Incidence of ADR was found to be significantly higher in patients of low socioeconomic status, rural residence and on polypharmacy ( $\mathrm{p}$ value $0.001,0.006$ and $<0.001$ respectively). This might be related to improper drug storage, handling or compliance, which is difficult to ascertain however.

Within the study population, lower mean scores were noted for the general health and near activities domains of the vQOL, irrespective of ADR. Several previous studies 4,13,14 have reported visual acuity loss and advanced field loss as the main causes associated with lower vQOL in POAG. However, according to Odberg et al,15,16 QOL impairment occurs much earlier; at the time of diagnosis. We could not do a subgroup analysis based on the staging of the disease as our survey based data did not include the clinical staging of glaucoma.

The most remarkable finding in our study was the statistically significant lower composite QOL scores for patients with ADR upon regression analysis ( $p$ value 0.03 ). The rural area of residence, prolonged duration of treatment for glaucoma (More than 5 years) and polypharmacy also showed significant associations with poor vQOL, independent of ADR ( $\mathrm{p}$ value $0.001,0.002$ and 0.015 respectively).

\section{CONCLUSION}

The incidence of ADR is fairly common, affecting nearly three fourth of the patients on topical anti-glaucoma medications. Our study clearly demonstrates an unequivocal negative impact of $\mathrm{ADR}$ on the vision-related quality of life, emphasising the integration of proper patient education and counselling in the longterm management of glaucoma.

\section{ACKNOWLEDGEMENTS}

We acknowledge all our patients for their kind co-operation and other supporting staff for their contribution in the study.

\section{REFERENCES}

[1] Quigley HA, Broman AT. The number of people with glaucoma worldwide in 2010 and 2020. Br J Ophthalmol 2006;90(3):262-7.

[2] Tham YC, Li X, Wong TY, et al. Global prevalence of glaucoma and projections of glaucoma burden through 2040: a systematic review and meta-analysis. Ophthalmology 2014;121(11):2081-90.

[3] Rewri P, Kakkar M. Awareness, knowledge, and practice: a survey of glaucoma in North Indian Rural residents. Indian J Ophthalmology 2014;62(4):482-6.

[4] Quaranta L, Riva I, Gerardi C, et al. Quality of life in glaucoma: a review of the literature. Adv Ther 2016;33(6):959-81.

[5] Ramakrishnan R, Nirmalan PK, Krishnadas R, et al. Glaucoma in a rural population of southern India: the Aravind comprehensive eye survey. Ophthalmology 2003;110(8):1484-90.

[6] Barber BL, Strahlman ER, Laibovitz R, et al. Validation of a questionnaire for comparing the tolerability of ophthalmic medications. Ophthalmology 1997;104(2):334-42.

[7] Barber BL, Santanello NC. Relating spontaneous adverse experience reports to scores on a questionnaire querying tolerability. International Journal of Clinical Pharmacology and Therapeutics 1995;33(11):598-604.

[8] Nordmann JP, Auzanneau N, Ricard S, et al. Vision related quality of life and topical glaucoma treatment side effects. Health and Quality of Life Outcomes 2003;1:75.

[9] Mangione CM, Lee PP, Gutierrez PR, et al. Development of the 25-item National Eye Institute Visual Function Questionnaire. Archives of Ophthalmology 2001;119(7):1050-8. 
[10] Pisella PJ, Pouliquen P, Baudouin C. Prevalence of ocular symptoms and signs with preserved and preservative free glaucoma medication. $\mathrm{Br} J$ Ophthalmol 2002;86(4):418-23.

[11] Alaei M, Najmi AK, Kausar $H$, et al. A prospective research study of anti-glaucoma drugs prescribing, utilization pattern and adverse drug reaction recording in a university hospital. Drug Res (Stuttg) 2015;65(3):164-8.

[12] Bhatt R, Whittaker KW, Appaswamy S, et al. Prospective survey of adverse reactions to topical anti-glaucoma medications in a hospital population. Eye (Lond) 2005;19(4):392-5.

[13] Mills RP, Janz NK, Wren PA, et al. Correlation of visual field with quality-of-life measures at diagnosis in the Collaborative Initial Glaucoma Treatment Study (CIGTS).J Glaucoma 2001;10(3):192-8.
[14] Lichter PR, Musch DC, Gillespie BW, et al. Interim clinical outcomes in the Collaborative Initial Glaucoma Treatment Study comparing initial treatment randomized to medications or surgery. Ophthalmology 2001;108(11):1943-53.

[15] Odberg T, Jakobsen JE, Hultgren SJ, et al. The impact of glaucoma on the quality of life of patients in Norway. II. Patient response correlated to objective data. Acta Ophthal Scand 2001;79(2):121-4.

[16] Odberg T, Jakobsen JE, Hultgren SJ, et al. The impact of glaucoma on the quality of life of patients in Norway. I. Results from a self-administered questionnaire. Acta Ophthal Scand 2001;79(2): 116-20. 